\title{
Chemical Regulations in China: An Overview
}

\author{
Siming Sun*
}

\section{Introduction}

China has been developing and reforming its chemical regulations against a background of rising environmental concerns and a number chemicals accidents. The legal system of chemical regulation in China now consists of laws, administrative regulations, departmental rules and standards. Diverse chemical regulations and administrative application procedures are governed by different authorities. In January 2019, the Chinese Ministry of Ecology and Environment published the draft regulation on Environmental Risk Assessment and Control of Chemical Substances with the aim of establishing an overall system for managing of both existing and new chemical substances. This draft regulation will bring many changes to the current chemical management system in China by the time it is implemented.

\section{Implementation of GHS in China}

The United Nations Globally Harmonized System (UN GHS) was introduced in China under the national standards, known as GB standards. ${ }^{1}$ The implementation was based on the 4 th revision of UN GHS. China GHS comprises all the 28 hazards in the UN GHS 4 th revision. Mandatory and recommended national standards for classification, labelling, safety

DOI: $10.21552 / \mathrm{icrl} / 2019 / 2 / 9$

* International Project Coordinator at UMCO GmbH. For Correspondence: <s.sun@umco.de>

1 Mandatory standards are prefixed ' $G B$ ' and recommended standards are prefixed ' $\mathrm{GB} / \mathrm{T}$ '.

2 These standards include: GB30000.2-2013 - GB30000.29-2013 Rules for classification and labelling of chemicals, mandatory since November 1st 2014. The series standard contain 28 compulsory national standards, which are composed of every individual adopted hazards, starting from the hazard of 'explosives' to 'hazardous to the ozone layer'. GB13690-2009 General rule for classification and hazard communication of chemicalsGB/T16483-2008 Safety Data Sheet for chemical products content and order of sectionsGB/T17519-2013 Guidance on the compilation of safety data sheet for chemical productsGB15258-2009 General rules for preparation of precautionary labels for chemicalsGB/T 22234-2008 Labelling of chemicals according to the GHSGB 190-2009 Packing symbol of dangerous goods datasheets and packaging were published from 2008 to $2014 .^{2}$ The entry into force of Decree No 591 on 1 December 2011 signified the formal implementation of GHS in China.

\section{Authorities}

Twelve authorities participated in the implementation, with the MIIT acting as the leading authority, developing the national action plan and the key regulatory scheme to implement GHS. However, in March 2018, a major reshuffle of state authorities was announced. The Ministry of Ecology and Environment (MEE) took over all responsibilities previously designated to the Ministry of Environmental Protection (MEP). The Solid Waste and Chemicals Management Center (SCC), a subordinate organization of MEE, was tasked with the responsiblitly for notification of new substances. The Safety Administration of Work Safety (SAWS) together with other authority units, were merged into the newly established Ministry of Emergency Management (MEM), which is primarily responsible for workplace safety and all kinds of emergencies management. The National Registration Center of Chemicals (NRCC), a subordinate organization of MEM, is the competent authority for registration of hazardous chemicals.

\section{Decree No. 591}

The Regulation on the Control over Safety of Hazardous Chemicals, mostly known as 'Decree No. 591', is the most fundamental regulation in regard to Chinese chemical legislation. With the aim of strengthening the safety administration of hazardous chemicals, preventing and reducing accidents and protecting the life and property of people, Decree No. 591 was promulgated by the Chinese State Council and came into effect on 11 December 2011. Within the framework of Decree No. 591, essential requirements and obligations for manufacturing, storage, handling, use, operation and transportation of hazardous chemicals are regulated. 
Three pillars represent the key requirements of this regulation. Firstly, the classification, labelling and safety datasheets must adhere to the GB standards. Secondly, there are basically two types of official reporting obligations of chemicals outlined in Decree No.591, the registration of hazardous chemicals and the notification of new substances. Thirdly, companies dealing with hazardous chemicals must apply for administrative licenses, including safety production licenses, safety use licenses, road transportation licenses.

\section{Registration of Hazardous Chemicals}

Article 67 of Decree No.591 regulates the obligation to register hazardous chemicals. SAWS Order $53^{3}$ elaborates on the registration requirements. Hazardous chemicals are defined as entire products, including substances and mixtures. Domestic manufacturers must register prior to the completion of a newly built plant and domestic importers need to register prior to any import activities. Foreign companies cannot register directly, this must be carried out through domestic importers.

The Inventory of Hazardous Chemicals was published by SAWS and came into force on 1 May 2015. The inventory contains 2828 entries with 81 GHS classifications involved. The chemicals listed in the inventory consist of hazardous substances and certain hazardous mixtures. These mixtures are defined in the 2828th entry and contain mostly flammable solvents with flash points no more than $60^{\circ} \mathrm{C}$. All listed hazardous chemicals mixtures corresponding to the $70 \%$ principle $^{4}$ are obliged to be registered. Chemicals not included in the inventory but identified as hazardous chemicals through hazard identification principle ${ }^{5}$ need to be registered too. It is worth noting that a $24 \mathrm{~h}$ hour emergency telephone number within the territory of China is required both for the SDS/label and for registration itself.

\section{Notification of New Chemical Substances in China}

\section{Statistics}

In 2018 MEE published the overall statistics for new substances notification. As shown in the Diagram 1,
152 cases of Regular Notification were submitted and approved. Compared to this, a significantly larger number of Simplified Notifications (2883) were approved, of which approximately $84.5 \%$ were affiliated to special cases. Simplified Notification Special Case is the most commonly applied type of notification that companies are familiar with. Diagram 2 represents the percentage of different types of Simplified Notification Special Case. The most frequent special case notification $(71 \%)$ are 'polymers with $<2 \%$ new monomer'. This is followed by 'PLC polymers of low concern' (15\%). Furthermore, MEE received 1045 applications of Scientific Research Record Notification (SRRN) within the second half of $2018 .^{6}$

\section{IECSC}

The Inventory of Existing Chemical Substances in China, mostly known as IECSC, was officially published in January 2013 by the Ministry of Environmental Protection. The IECSC is a dynamic and growing Inventory. The original 2013 Inventory includes 45,612 substances and has been added to three times, in 2016 (with 31 substances) ${ }^{7}$, in November 2018 (with 45 substances) ${ }^{8}$ and in January 2019 (with 28 substances) $)^{9}$. The IECSC is an indicator to determine if a chemical substance requires notification or not. As a positive inventory, all listed substances are considered as existing substances and are exempted from notification. All non-listed substances are regarded as new substances, which require notifica-

3 Measures on the registration of hazardous chemicals became valid on 1 August 2012.

4 A chemical mixture is subject to registration if the major compositions are listed in the Inventory of hazardous chemicals, and the sum of their mass fractions or volume fractions is no less than $70 \%$

5 It applies to 81 out of 95 adopted GHS hazard classifications.

6 MEE, Announcement on 2 February 2011, <http://gts.mee.gov.cn/ hxphjgl/xhxwz/201902/t20190211_692069.shtml>

7 MEE, Announcement No 20, 2016 <http://www.mee.gov.cn/gkml/ hbb/bgg/201603/t20160315_332884.html> accessed 1 May 2019.

8 MEE, Announcement No 58, 2018 <http://www.mee.gov.cn/ xxgk2018/xxgk/xxgk01/201811/t20181130_676779.html>accessed 1 May 2019.

9 MEE, Announcement No 1, 2019 <http://www.mee.gov.cn/ xxgk2018/xxgk/xxgk01/201901/t20190117_689881.html>accessed 1 May 2019. 


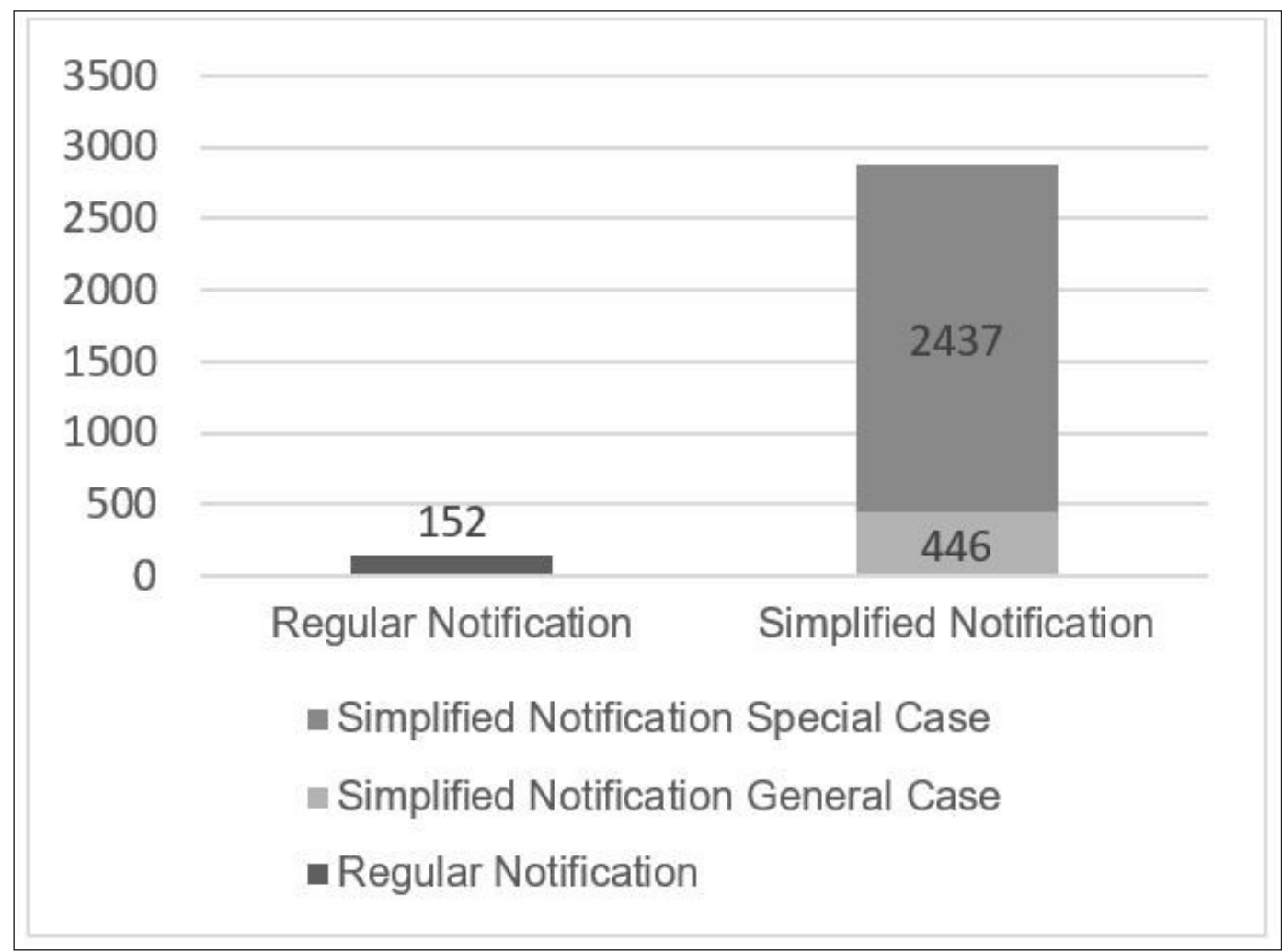

Diagram 1: Numbers of Notifications Approved by MEE in 2018

tion. After 5 years, notified new substances through the 'Regular Notification' process are listed in the IECSC and become existing substances. Through a process of SRRN or Simplified Notification notified substances are not listed in the IECSC. Once substances are listed, there will be no more subsequent notification obligations. All the running notification processes can be terminated and the IECSC is publicly available. However, there are 3,270 substances $(7 \%)$ in the inventory managed confidentially and they contain only serial numbers and generic names. The common approach to avoid uncertainty about the status of a substance is a formal inquiry to the SCC.

\section{Notification}

The revised Measures on the Environmental Management of New Chemical Substances, well known as the MEE Order 7 or China REACH, became valid on 15 October 2010 and govern the notification for new substances. New substances refer to all substances that are not listed in the IECSC including:

- new substances used as raw materials or intermediates of pharmaceuticals, pesticides, veterinary medicine, cosmetics, food additives, feed additives, etc.

- new substances as functional ingredients of surfactant, plasticizer, preservative, dispersant, flame retardant, etc.

- new substances of variable composition, complex reaction products, substances without unique structural formula and polymers.

- new substances intended to be released from articles.

New substances exempted from notification are:

- finished products subject to other laws and regulations, such as pharmaceuticals, pesticides, veterinary medicines, cosmetics, food and food additives, feed and feed additives, radioactive materials, military products, explosives, tobacco, etc. 


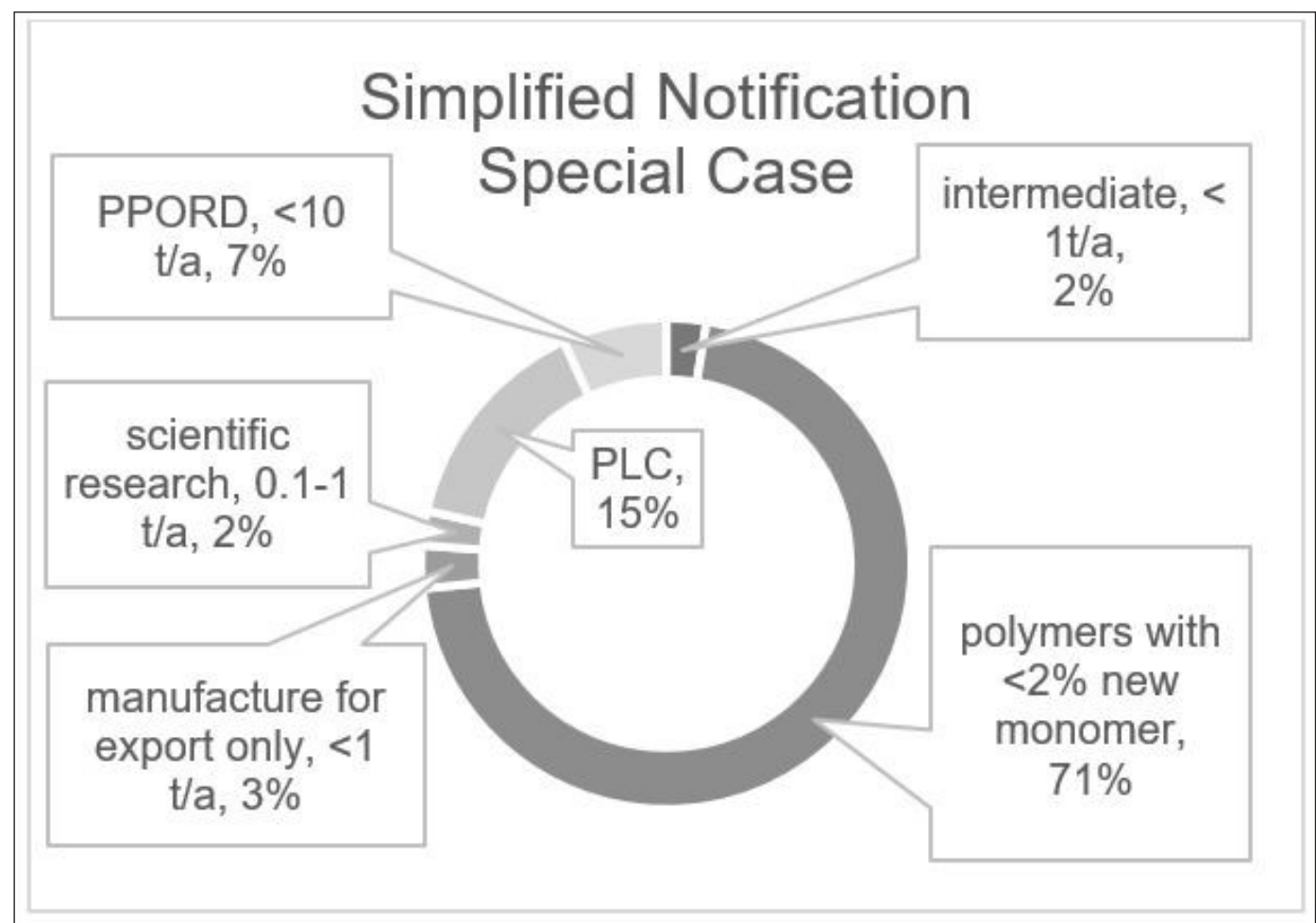

Diagram 2: Different Types of Simplified Notification Special Cases in 2018

- naturally occurring substances.

- substances of non-commercial purpose or non-intentional production.

- special categories such as glass, cement, alloys, non-isolated intermediates, articles

According to Article 5 ofthe MEE Order 7, manufacturers and importers of new substances must carry out a notification and apply for a certificate before a new chemical substance can be produced or imported or placed on the Chinese market. The competent authority for notification is the SCC, a subordinate authority of MEE. Domestic manufacturers, importers and direct foreign exporters can act as notifiers. Foreign exporters acting as notifiers cannot carry out the notification directly. Instead, they must appoint a qualified domestic agency as their 'representative', which is similar to the 'Only Representative' concept under EU REACH. The MEE Order 7 also requires an eligible representative to be a registered legal entity based within the territory of China, possessing registered capitals above 3 Million CNY (approximately $€_{380,000)}$ and have had no violations against MEE Order 7 in the past three years.
There is no minimum tonnage threshold for notification. Only the types of notification differ from each other according to tonnage. Table 1 displays the three notification types with their sub categories.

\begin{tabular}{|c|c|}
\hline $\begin{array}{l}\text { Scientific Re- } \\
\text { search } \\
\text { Record Notifi- } \\
\text { cation (SR- } \\
\text { RN) }\end{array}$ & $\begin{array}{l}\text { testing samples for eco-toxicity tests in test } \\
\text { institutions in china } \\
\text { for research purposes }(<0.1 \mathrm{t} / \mathrm{a})\end{array}$ \\
\hline $\begin{array}{l}\text { Simplified } \\
\text { Notification }\end{array}$ & $\begin{array}{l}\text { General Case: }<1 \mathrm{t} / \mathrm{a} \\
\text { Special Case: } \\
\text { intermediates, }<1 \mathrm{t} / \mathrm{a} \\
\text { manufacturing only for export, }<1 \mathrm{t} / \mathrm{a} \\
\text { for research purposes, } 0.1-1 \mathrm{t} / \mathrm{a} \\
\text { polymers with }<2 \% \text { new monomer; poly- } \\
\text { mer of low concern } \\
\text { PPORD, no longer than } 2 \text { years, }<10 \mathrm{t} / \mathrm{a}\end{array}$ \\
\hline $\begin{array}{l}\text { Regular Noti- } \\
\text { fication }\end{array}$ & $\begin{array}{l}\text { Level 1: 1-10 t/ a } \\
\text { Level 2: } 10-100 \mathrm{t} / \mathrm{a} \\
\text { Level 3: } 100-1000 \mathrm{t} / \mathrm{a} \\
\text { Level 4: > 1000 t/ a } \\
\text { Special types of Joint Notification, Serial } \\
\text { Notification and Repeated Notification are } \\
\text { available, but not mandatory. }\end{array}$ \\
\hline
\end{tabular}


Table 1: Notification types under China New Chemical Substances Notification

\section{Data Requirements}

The new minimum data requirements ${ }^{10}$ for toxicity and eco-toxicity tests and exemption conditions for physical-chemical, toxicity and eco-toxicity data, become valid on 15 October 2017. In the case of Scientific Research Record Notification (SRRN) and Simplified Notification Special Cases no testing data is required. However, in the case of a Simplified Notification General Case, specific eco-toxicity test data according to substance property is required. In regard to the Regular Notification risk assessment reports, a China GHS complied classification, a label, a safety datasheet and a complete set of test reports consisting of physical-chemical, toxicity and eco-toxicity data is required. The number of endpoints depends on the tonnage level. Generally, a notification dossier is composed of a notification form attached to the required test data, a signed authorisation letter, a business license, a legal entity certificate and a Power of Attorney (POA) when an 'Only Representative' is involved.

Test results from foreign OECD-GLP institutions are acceptable for the notification in China, except in certain eco-toxicity tests. According to Article 10 and 12 of the MEE Order 7, certain specific eco-toxicity tests must be performed in Chinese test institutions with Chinese test organisms. This includes acute aquatic toxicity test, test of bio degradation (ready or inherent) and terrestrial toxicity for insoluble compounds and etcetera accordingly. By tonnage level 1 , at least one acute aquatic toxicity test should be submitted and acute fish toxicity is preferred. With every increasing tonnage levels, one additional acute aquatic toxicity test is required. The MEE abolished the system for reviewing and publishing the list of eligible test institutions from 1 April 2017 on. ${ }^{11}$ Domestic test institutions that provide tests for notification

10 MEE, Announcement No 42, 2017 <http://www.mee.gov.cn/gkml/ hbb/bgg/201709/t20170905_420903.htm> accessed 1 May 2019.

11 MEE, Announcement No 85, 2016 <http://www.mee.gov.cn/gkml/ hbb/bgg/201701/t20170105_393888.htm> accessed 1 May 2019

12 Information regarding GLP self-declaration submitted by test institutions is available at <http://114.251.10.152:8087/glp/gg/ pubquery2> accessed 1 May 2019. should be accredited to the CMA (China Metrology Accreditation). Domestic institutions providing ecotoxicity tests should submit a China-GLP self-declaration on the SCC website ${ }^{12}$ and meanwhile publish extensive information regarding testing items, qualifications and equipment of the institutions.

\section{Further Developments}

The management of existing substances is being enhanced in China. Significant lists governing existing substances have been published in recent years. For example, the List of Priority Controlled Chemicals ( $1^{\text {st }}$ Batch) with 22 types of chemicals, which are subject to risks control measures, was published on 28 December 2017. The Inventory of Severely Restricted Toxic Chemicals came into force on 1 January 2018, and contains 10 types of chemicals with 38 CAS numbers controlled by the Stockholm Convention, the Rotterdam Convention and the Minamata Convention on Mercury. The Import and export of these listed chemicals are only authorised for specific uses.

The MEE published the draft of a new regulation named Regulations on Environmental Risk Assessment and Control of Chemical Substances on 8 January 2019 for public consultation. From the perspective of China's legal structure, the new regulation will be affiliated with the second legal level as an 'administrative regulation' analogous to 'Decree No. 591'. The new regulation aims to establish a comprehensive and complete legal system for environmental risk assessment and control of existing substances, which are currently being insufficiently administrated. This is regarded as a milestone to achieve effective management of existing substances in China. Likewise, the draft regulation brings changes to the approval procedure for new chemicals notification. The MEE Order 7, which is currently under revision, will become an inferior order under this new regulation and the revised Order 7 will be aligned with the provision changes in the new regulation. According to the draft, the current Scientific Research Record Notification (SRRN) and Simplified Notification process will be replaced by a 'Record Filing' system in the future, which will facilitate the notification and reduce companies' burdens. The public consultation period on the draft ended on 20 February 2019. As of yet there is no clear statement about when the new regulation will become valid. 


\section{Conclusions}

For better compliance, it is advisable that enterpris es actively pay attention to legal changes and establish open and engaged communication with a local representative agency and authorities to understand regulatory requirements and overcome language barriers. Please be aware that China GHS is not harmonized with the EU CLP. Enterprises should adapt the classification, labelling and safety datasheets of chemicals in accordance with GB standards requirements. To comply with notification for new chemicals, lots of aspects should be considered. A formal inquiry to the SCC is recommended to determine whether a substance is subject to notification. One must take into account that certain eco-toxicity tests must be performed in Chinese test institutions. The SRRN for test samples should be submitted before carrying out the eco-toxicity tests in China. Enterprises should be prepared for the authority asking for more data beyond minimum data requirements and being challenged with further questions. Abstract or full translation of English materials into Chinese language is needed and translations should in line with original materials to avoid misunderstandings and notification postponement. In order to keep a substance confidential, both Chinese and English generic names should be submitted. Chinese generic name must adhere to HJ/T420-2008. ${ }^{13}$ Critical information of substances, which may pose hazardous to human health and the environment, must be revealed. Enterprises should attach great importance to post-notification obligations to avoid non-compliance. This includes, but is not limited to, annual reports, first activity reports, indications of hazardous properties of new substance in safety datasheets and reporting of newly discovered hazardous properties of the new substance.

$13 \mathrm{HJ} / \mathrm{T} 420-2008$ The guidelines for the generic name of new chemical substances, a recommended industrial standard implemented since April 12008. 